\title{
ANALISIS METODE PENGOLAHAN SAMPAH ORGANIK MENGGUNAKAN LARVA BLACK SOLDIER FLY
}

\section{ANALYSIS OF ORGANIC WASTE PROCESSING METHODS USING BLACK SOLDIER FLY LARVA}

\author{
Aulia Annas Mufti ${ }^{1}$ \\ ${ }^{1}$ Program Studi Teknik Lingkungan, Institut Teknologi Sumatera, Jalan Terusan Ryacudu, Lampung Selatan \\ Email : aulia.mufti@tl.itera.ac.id
}

\begin{abstract}
ABSTRAK
Berdasrkan komposisinya sampah padat perkotaan di Indonesia merupakan sampah organik dengan presentase sekitar $70 \%$ dan sampah anorganik sekitar $28 \%$, sisanya adalah sampah B3 yang pengolahannya dilakukan secara khusus. Pengolahan sampah organik dapat dilakukan menggunakan bantuan larva BSF agar proses pengolahannya lebih cepat dan efisien. Dalam mengolah sampah organik menggunakan larva BSF terdapat banyak metode yang digunakan. Oleh karena itu, penelitian ini bertujuan untuk menganalisi metode-metode yang dapat digunakan untuk mengolah sampah organik menggunakan larva BSF. Metode penelitian yang digunakan adalah systematic review. Berdasarkan hasil pembahasan dalam mengolah sampah organik menggunakan larva BSF terdapat dua metode yaitu sistem terbuka dan sistem tertutup. Sistem terbuka dapat digunakan untuk mengolah sampah dengan kapasitas kecil hingga menengah sedangkan sistem tertutup dapat dingunakan untuk mengolah sampah dengan kapasitas menenga ke besar. Jika akan memilih metode untuk mengolah sampah menggunakan larva BSF dapat mempertimbangkan kekurangan dan kelebihan dari masing-masing metode.
\end{abstract}

Kata kunci: BSF; maggot; sampah organik

\section{ABSTRACT}

Based on its composition, urban solid waste in Indonesia are organic waste with a percentage of about $70 \%$ and anorganic waste around $28 \%$, the residu are B3 waste which are processed specifically. Organic waste processing can be done using BSF larvae so that the process was faster and more efficient. In processing organic waste using BSF larvae, there are many methods used. Therefore, this study aims to analyze the methods that can be used to treat organic waste using BSF larvae. The research method used is a systematic review. Based on the results in processing organic waste using BSF larvae, there were two methods, open system and closed system. An open system can be used to treat small to medium capacity waste, while a closed system can be used to treat medium to large capacity waste. To choose a waste treatment method using BSF larvae can consider the advantages and disadvantages of each method.

Keywords: BSF; maggot; organic waste

\section{Pendahuluan}

Permasalahan sampah padat di perkotaan menjadi isu lingkungan di banyak negara, baik negara maju ataupun negara berkembang. Pengelolaan sampah padat adalah suatu masalah yang harus ditangani secara serius karena volume sampah tiap tahunnya terus meningkat sejalan dengan bertambahnya jumlah penduduk. Selain menjadi vektor penyebaran penyakit, bau yang tidak sedap, sampah juga dapat mengakibatkan semakin parahnya bencana alam yaitu banjir (Kahar dkk., 2020). 
Berdasrkan komposisinya sampah padat perkotaan di Indonesia merupakan sampah organik dengan presentase sekitar $70 \%$ dan sampah anorganik sekitar $28 \%$, sisanya adalah sampah B3 yang pengolahannya dilakukan secara khusus (Damanhuri dkk., 2014). Pemilahan sampah padat perkotaan yang dilakukan pada TPST umumnya masih dilakukan secara manual. Karenanya membutuhkan waktu yang lama, maka akan terjadi penumpukan. Hal tersebut dapat menimbulkan bau yang tidak sedap. Untuk mengurangi penumpukan dan memanfaatkan sampah-sampah organik tersebut, maka dilakukan biokonversi sampah organic perkotaan menggunakan larva Black Soldier Fly (Hermetia illucens) di TPST. Pengolahan sampah organik dapat dilakukan menggunakan bantuan larva BSF agar proses pengolahannya lebih cepat dan efisien. Dalam mengolah sampah organik menggunakan larva BSF terdapat banyak metode yang digunakan. Oleh karena itu, penelitian ini bertujuan untuk menganalisi metodemetode yang dapat digunakan untuk mengolah sampah organik menggunakan larva BSF.

\section{Metodologi Penelitian}

Metode penelitian yang digunakan adalah systematic review. Systematic review dimulai dengan membuat protokol penelitian systematic review dan tahap berikutnya melaksanakan penelitian systematic review. Menurut Perry dan Hammond (2016), urutan proses penelitian systematic review adalah sebagai berikut:

a. Indentifikasi pertanyaan penelitian

b. Mengembangkan protokol.

c. Menetapkan lokasi data-base hasil penelitian sebagai wilayah pencarian.

d. Seleksi hasil-hasil penelitian yang relevan.

e. Pilih hasil-hasil penelitian yang berkualitas.

f. Ekstraksi data dari studi individual.

g. Sintesis hasil dengan metode meta-analisis atau metode naratif.

h. Penyajian hasil.

\section{Hasil dan Pembahasan}

Penggunakan larva lalat untuk pengolahan sampah organik telah dimulai hampir 100 tahun yang lalu. Menurut Diener (2010), banyak penelitian laboratorium telah menunjukkan bahwa beberapa spesies lalat dapat digunakan untuk biodegradasi limbah organik, seperti lalat tentara hitam Black Soldier Fly (Hermetia illucens) merupakan serangga yang paling banyak dipelajari. Larva BSF menerima variasi bahan organik yang mudah membusuk. Hasil residu biokonversi menggunakan larva BSF menghasilkan kompos yang lebih baik daripada pupuk kotoran hewan atau residu tanaman (Diener, 2010).

Menurut Kenis dkk. (2018), Sistem produksi BSF dapat dipisahkan menjadi dua kategori. Sistem pertama dikembangkan sejak tahun 1970-an terdiri dari mengekspos substrat ke alam BSF betina untuk bertelur. Sementara ini masih digunakan untuk perorangan pada skala rumah tangga dan peternak hewan skala rumahan. Sistem kedua yaitu didasarkan pada sistem pemeliharaan dewasa terpisah untuk produksi telur. Saat ini, sistem yang kedua ini, digunakan pada sektor menengah dan skala besar. Sistem pertama dapat dikatakan sebagai sistem terbuka karena menggunakan telur BSF yang ada di alam liar sedangkan sistem kedua dapat dikatakan sebagai sistem tertutup karena menggunakan telur BSF yang dibudidayakan.

\subsection{Metode Pengolahan Sampah dengan Sistem Terbuka}

Berdasarkan Yuwono dan Mentari (2018), pengolahan sampah organik rumah tangga menggunakan larva BSF dapat berlangsung pada bak yang terbuat dari pasangan bata dan plester. Volume bak kompos tersebut $0.273 \mathrm{~m}^{3}$ dengan dimensi $600 \mathrm{~mm}$ x $700 \mathrm{~mm} \times 650 \mathrm{~mm}$ dapat menampung sampah segar sebanyak 25-30 kg per satu bak. Untuk rumah tangga beranggotakan 4 orang, satu bak kompos dapat menampung sampah rumah tangga selama 6 bulan. Siklus hidup BSF berlangsung secara alami tanpa ada treatment pada setiap fasenya. 
Berikut ini adalah desain yang digunakan Yuwono dan Mentari (2018) ditampilkan pada Gambar 1.

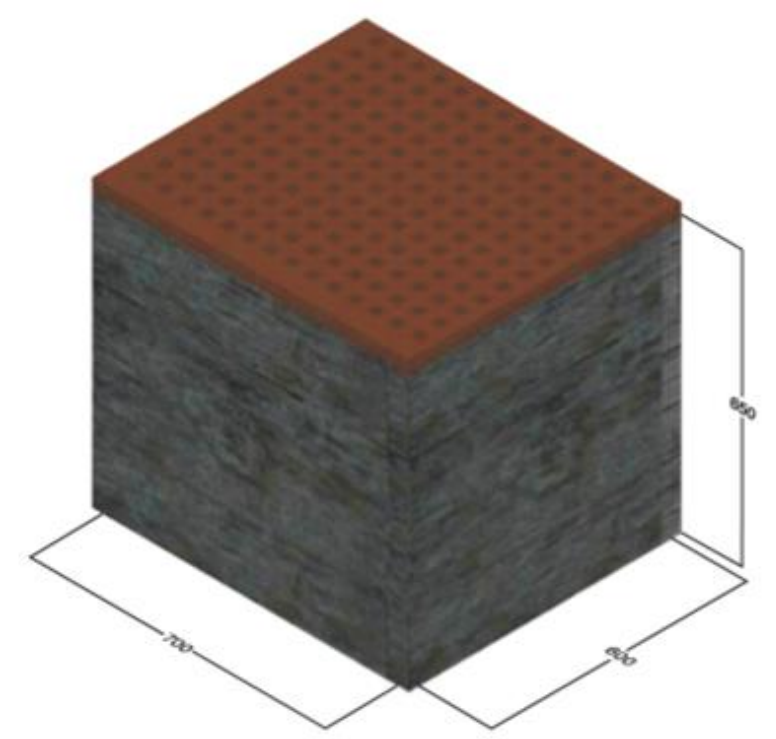

Gambar 1. Desain bak kompos menggunakan larva bsf

Nyakeri dkk. (2017), melakukan penelitian tentang budidaya BSF dengan sistem terbuka menggunakan wadah berdimensi $1 \mathrm{~m}$ x 0,5 $\mathrm{m}$ x 0,5 m. Wadah tersebut diisi attractant substrate untuk menarik betina BSF. Tabung plastik bergelombang berdiameter 0,5 inci ditempatkan di atas attractant substrate sebagai tempat menaruh telur. Telur-telur BSF didapatkan dari BSF yang ada di alam terbuka. Budidaya BSF dengan sistem terbuka ini tidak membutuhkan treatment. Berikut ini adalah gambar dari wadah yang digunakan dalam penelitian tersebut ditampilkan pada Gambar 2.

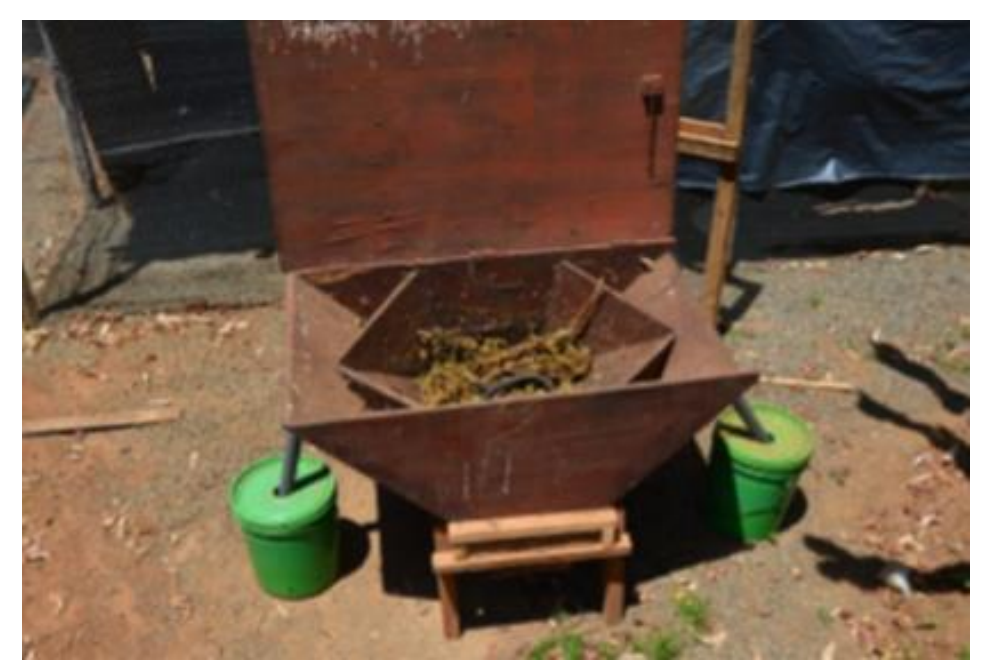

Gambar 2. Wadah budidaya BSF menggunakan bahan kayu

Bullock dkk. (2013), menyatakan bahwa untuk membudidayakan BSF dalam skala medium to small seperti pada rumah tangga dapat menggunakan tempat sampah plastik dengan kapasitas 20 gallon lalu diberi pipa PVC sebagai jalur migrasi prepupa menuju tempat pengumpul berupa ember dengan kapasitas 5 gallon. Pada dinding bak sampah bagian atas diberi potongan kardus sebagai tempat peletakan telur BSF. Alat budidaya BSF ini diletakan 
pada ruang terbuka agar BSF datang dan bertelur. Berikut ini merupakan gambar dari alat budidaya BSF dalam skala small to medium ditampilkan pada Gambar 3.

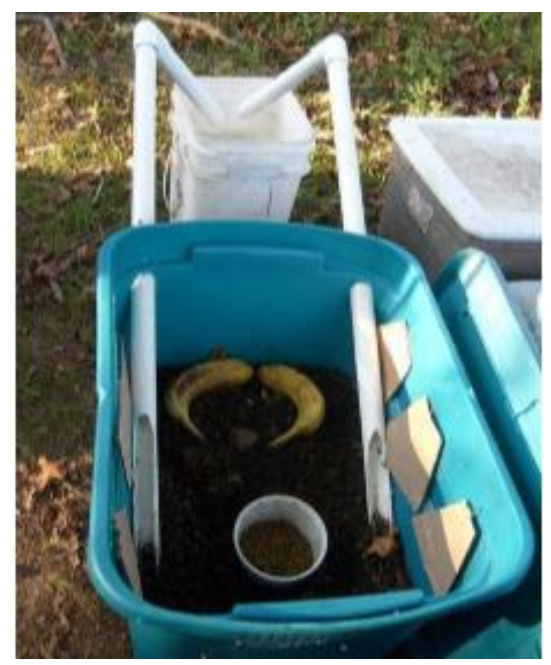

Gambar 3. Alat Budidaya BSF Skala Medium to Small

Menurut Park (2016), proses konversi sampah organik rumah tangga dapat mengunakan alat Biopod Plus Auto-Harvesting Grub Composter. Dimensi alat tersebut mempunyai tinggi 26,5 inch, panjang 15,5 inchi, dan lebar 16 inchi. Bagian Biopod terdiri dari body, main lid kit, inner convenience lid, drainage plate, drainage pad, harvest bucket, dan external drainage assembly. Tepi bagian dalam dari alat tersebut terdapat jalur migrasi prepupa dengan kemiringan $40^{\circ}$. Dalam hal kapasitas fungsional, alat ini dapat menampung maksimum $2,2 \mathrm{~kg}$ / 5 lbs per hari. Biokonversi diproyeksikan pada 15-20\% limbah makanan menjadi BSFL dan 3-5\% biokonversi sisa menjadi residu larva. Berikut ini merupakan gambar dari alat Biopod ditampilkan pada Gambar 4.
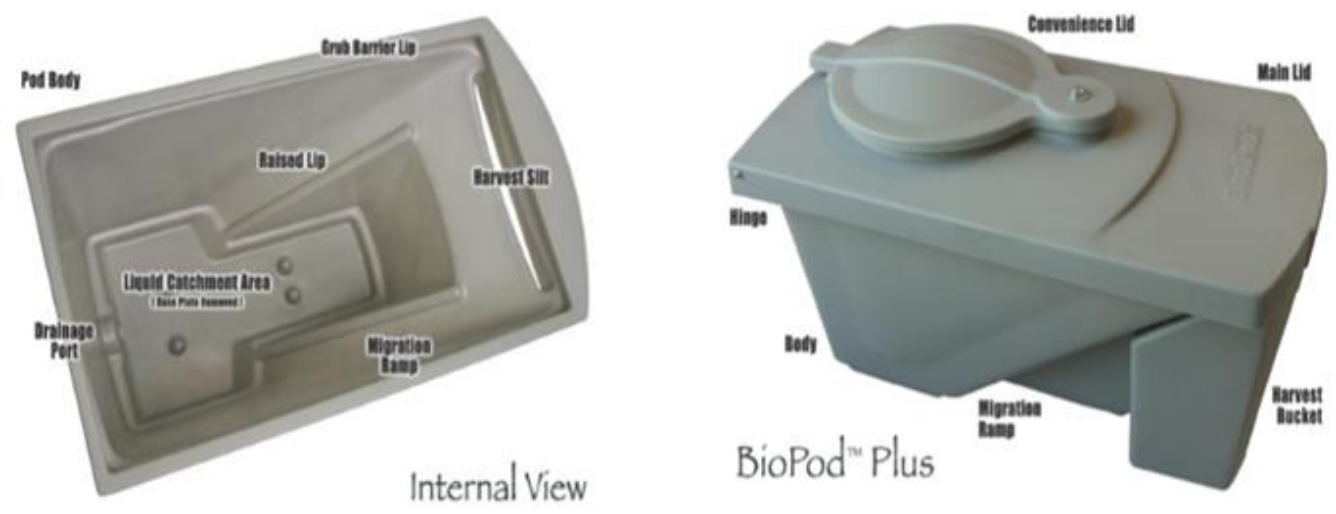

Gambar 4. Alat biopod plus auto-harvesting grub composter

\subsection{Metode Pengolahan Sampah dengan Sistem Tertutup}

Mutafela (2015), melakukan penelitian disebuah barak mengenai treatment sampah organik menggunakan BSF. Beberapa peralatan yang digunakan pada penelitian tersebut yaitu Feeding Bucket, Leachate Collection Bucket, Prepupae Collection Bucket, Pupa Bucket, dan Breeding Cage. Feeding Bucket berkapasitas 70 liter $(0,72 \mathrm{mx}$ 0,4 $\mathrm{m}$ x 0,39 m) dan transparan. Di dalamnya dilengkapi dua saluran keluar prepupa, masing-masing saluran terdapat dua jalur 
dengan lebar jalur 40mm dan terpasang pada sudut $45^{\circ}$. Prepupa yang keluar lalu ditampung dalam Prepupae Collection Bucket bervolume 5 liter. Prepupa yang sudah berubah menjadi pupa di masukan kedalam Pupa Bucket. Di ujung Feeding Bucket memiliki outlet untuk air lindi. Air lindi di tampung dalam Leachate Collection Bucket bervolume 10 liter. Untuk membesarkan lalat, kurungan $2 \mathrm{~m}$ x 0,9 m x $1 \mathrm{~m}$ dibuat dari bingkai kayu dan dipasang dengan jaring di sekelilingnya. Dalam proses biokonversi sampah organik menggunakan alat-alat tersebut dibutuhkan perlakuan tertentu pada setiap fase hidup BSF. Larva yang digunakan adalah larva yang sudah dibudidayakan dengan perlakuan tertentu bukan menggunakan larva yang berasal dari telur BSF liar. Berikut ini gambaran alat-alat yang digunakan untuk budidaya BSF ditampilkan pada Gambar 5 dan 6.

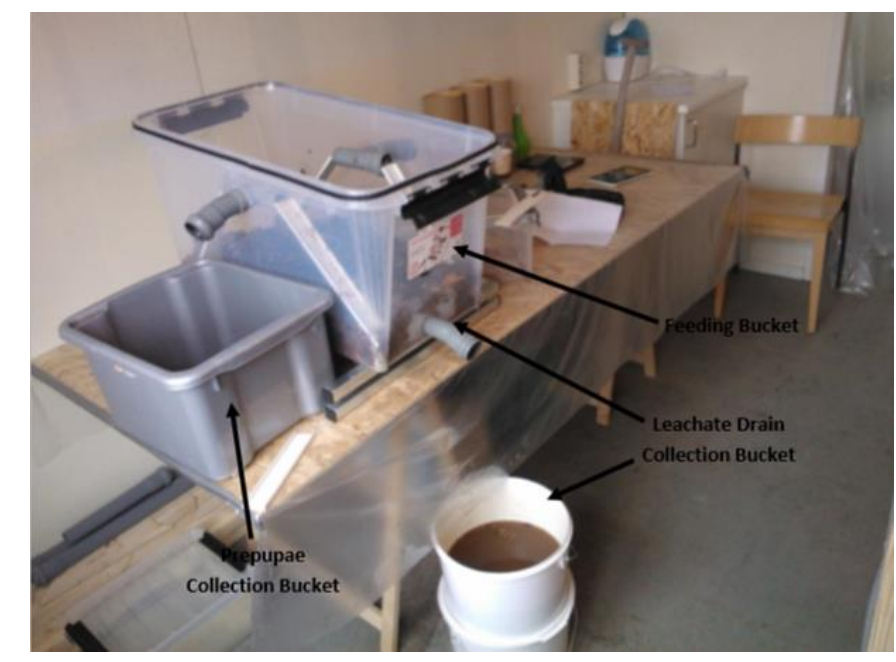

Gambar 5. Penempatan feeding bucket, leachate collection buckets dan prepupae collection buckets.

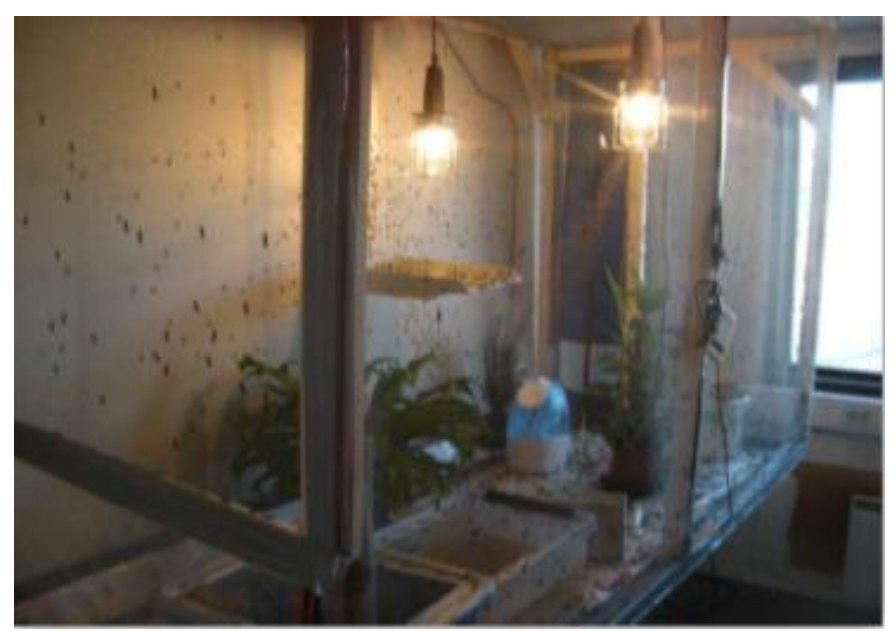

Gambar 6. Breeding cage

\subsection{Kekurangan dan Kelebihan dari Sistem Terbuka dan Tertutup}

Menurut Kenis dkk. (2018), Proses pengolahan sampah menggunakan larva BSF dengan sistem terbuka tidak dianggap cukup andal untuk mempertahankan produksi larva BSF secara teratur dan daur ulang limbah. Masalah utama pada sistem ini adalah bahwa wadah harus secara teratur dikosongkan dari kompos busuk (Nyakeri dkk., 2017), yang menyebabkan keterlambatan produksi karena periode persiapan telur memerlukan setidaknya 3 minggu (Kenis dkk., 2018). Lebih lanjut, ketersediaan terlur tergantung pada iklim setempat, oviposisi 
alami hanya dapat terjadi pada periode waktu terbatas selama setahun. Ini juga menyiratkan bahwa BSF berlimpah di lokasi. Pada sistem ini serangga selain BSF dapat datang pada alat biokonversi seperti Lalat Rumah Umum, Lalat Botol Hijau, Blowflies dan Lalat Pasir (Nyakeri dkk., 2016). Beberapa lalat tersebut merupakan spesies yang terlibat dalam masalah kesehatan, yaitu sebagai vektor penularan penyakit (Safitri dkk., 2017). Kelebihan dari sistem ini yaitu perlakuan yang dilakukan terhadap fase hidup BSF sangat sederhana. Selain itu, untuk menjalankas sistem ini dibutuhkan modal uang yang relative sedikit dibandingkan dengan sistem tertutup.

Berdasarkan Kenis dkk. (2018), proses pengolahan sampah menggunakan larva BSF dengan sistem tertutup dilakukan dengan pemeliharaan lalat dewasa untuk memproduksi telur BSF. Siklus hidup BSF pada sistem ini dapat dilakukan pada tempat tertutup yang sudah direkayasa sesuai dengan lingkungan hidup BSF. Kekuranga dari sistem ini adalah membutukan beberapa alat untuk merekayasa siklus hidup BSF sehingga perlu menyediakan tempat budidaya BSF yang sesuai dengan dimensi alat-alat yang dipakai. Selain itu, diperlukan beberapa perlakuan tertentu pada setiap fase hidup BSF. Kelebihan dari sistem ini yaitu populasi BSF dapat dikontrol, tidak tergantung dengan kondisi lingkungan sekitar karena habitat dan kondisi lingkungan direkayasa sesuai dengan kebutuhan hidup BSF

\section{Kesimpulan}

Berdasarkan pembahasan di atas dapat disimpulkan bahwah dalam mengolah sampah organik menggunakan larva BSF terdapat dua metode yaitu sistem terbuka dan sistem tertutup. Sistem terbuka dapat digunakan untuk mengolah sampah dengan kapasitas kecil hingga menengah sedangkan sistem tertutup dapat dingunakan untuk mengolah sampah dengan kapasitas menenga ke besar. Dari kedua metode tersebut memiliki kekurangan dan kelebihan masing-masing sehingga jika akan memilih metode untuk mengolah sampah menggunakan larva BSF dapat mempertimbangkan kekurangan dan kelebihan dari masing-masing metode.

\section{Daftar Pustaka}

Bullock, N., Chapin, E., Evans, A., Elder, B., Givens, M., Jeffay, N., Pierce, B., \& Robinson, W. (2013). The black soldier fly How- to-guide.

Damanhuri, E., Handoko, W., \& Padmi, T. (2014). Municipal solid waste management in Indonesia. In Environmental Science and Engineering (Subseries: Environmental Science). Springer.

Diener, S. (2010). Valorisation of Organic Solid Waste using the Black Soldier Fly, Hermetia illucens, in Low and Middle-Income Countries (Issue 19330). ETH ZURICH.

Kahar, A., Busyairi, M., Sariyadi, S., Hermanto, A., \& Ristanti, A. (2020). Bioconversion of municipal organic waste using black soldier fly larvae into compost and liquid organic fertilizer. Konversi, 9(2), 35-40.

Kenis, M., Bouwassi, B., Boafo, H., Devic, E., Han, R., Koko, G., Koné, N., Maciel-Vergara, G., Nacambo, S., Pomalegni, S. C. B., Roffeis, M., Wakefield, M., Zhu, F., \& Fitches, E. (2018). Small-Scale Fly Larvae Production for Animal Feed. In Edible Insects in Sustainable Food Systems. Springer International Publishing.

Nyakeri, E. M., Ogola, H. J., Ayieko, M. A., \& Amimo, F. A. (2017). An open system for farming black soldier fly larvae as a source of proteins for smallscale poultry and fish production. Journal of Insects as Food and Feed, 3(1), 51-56.

Park, H. H. (2016). Black Soldier Fly Larvae Manual. University of Massachusetts Amherst.

Perry, A., \& Hammond, N. (2016). Systematic Reviews: The Experiences of a PhD Student: Psychology Learning and Teaching, 2(1), 32-35.

Yuwono, A. S., \& Mentari, P. D. (2018). Black Soldier Fly ( BSF ) Penggunaan Larva ( Maggot ) Dalam Pengolahan Limbah Organik. SEAMEO BIOTROP. 